\title{
Orkut: Motivos, Usos e Capital Social.
}

\author{
Alice Gabrielle de Paula alicegaby2@gmail.com \\ Renato trindade Ribeiro renatotrindaderibeiro@gmail.com \\ Cayley Guimarães profcayley@yahoo.com.br
}

\begin{abstract}
Resumo: Este estudo investiga os motivos, usos e ganhos de capital social do site de relacionamneto Orkut. Vale-se de variáveis da teoria de Capital Social e dos achados de Joinson (2008) para analisar conexões socias, identidades compartilhadas, conteúdo, investigação social, navegação e atualizações.
\end{abstract}

Palavras-Chave: Capital Social, Redes de Relacionamento online

Abstract. This study investigates reasons, uses and capital social gains of social networking site Orkut. It uses variables from Social Capital theory and other variables from Joinson (2008) to analyze social connection, shared identities, content, social investigation, social network surfing and status updating.

Key-words: Social Capital, Online Networks

\section{Introdução}

Sites de Redes Sociais de Relacionamentos, como o Orkut, têm crescido bastante nos últimos tempos. Nos Estados Unidos, o site Facebook cresceu $89 \%$ em 2007 e 500\% entre Novembro de 2006 e Maio de 2007 na Inglaterra. Este tipo de sistema de informação provê o usuário com espaço para perfil, conteúdos, mensagens, aplicações e conexões (ou "amigos"), que são a sua principal funcionalidade. $O$ crescimento rápido destes sites tem gerado também histórias de seqüestros, uso de informações pelas empresas na hora da contratação, pedofilia, roubo de identidade, e até mesmo vício. [JOINSON 2008]

As redes sociais tradicionais dão suporte emocional, acesso a recursos, relacionamentos, etc. Redes sociais similares têm sido encontradas no mundo virtual, em sites de relacionamentos, que também podem prover o usuário com capital social. [LAMPE et. AL 2006]. Qualquer que seja a perspectiva usada, o estudo destes sistemas de informação é de grande valia para a ciência e a sociedade. E, de acordo com Castells (1999), temos na rede as tecnologias da inteligência, que são instrumentos indispensáveis para se atingir os modos de desenvolvimento necessários a este século. $\mathrm{O}$ autor diz também que:
"o valor destas tecnologias está em possibilitar, tornar flexível e dinamizar a vida econômica, as relações sócias e o ambiente cultural, desde que haja competência de se disseminar e extrair informações relevantes".

Ora, temos que a sociedade não pode prescindir deste processo histórico, pois
"a tecnologia é a sociedade, e a sociedade não pode ser entendida ou representada sem suas ferramentas tecnológicas. [...] No novo modo informacional de desenvolvimento, a fonte de produtividade acha-se na tecnologia de geração de conhecimentos, de processamento de informação e de comunicação de símbolos." [Castells 1999] 
Para o autor, o conhecimento age no conhecimento e visa acúmulo de conhecimento, tornando-se o novo capital, gerando novos conhecimentos, que são acumulados como o novo bem, a nova fonte de riquezas.

Portanto, este estudo se vale da teoria de capital social, e dos fatores de análise de Joinson (2008) para agrupar perfis de usos e gratificações específicas de 115 brasileiros, usuários do Orkut.

\section{Análise (de Sites) de Redes Sociais de Relacionamentos}

As redes sociais tradicionais dão suporte emocional, acesso a recursos, relacionamentos, etc. Redes sociais similares têm sido encontradas no mundo virtual, em sites de relacionamentos, que também podem prover o usuário com capital social [LAMPE et. al2006]. Nos últimos anos temos observado a convergência das redes sociais, que têm ligado os seres humanos por milênios, com as redes tecnológicas, que conectam computadores na Internet. A tecnologia ampliou o processo, servindo de espaço virtual para conexões, comunidades virtuais, participação, etc.

Embora a tecnologia tenha introduzido mudanças, como na maneira como nos expressamos, ainda existem semelhanças: a maior mudança talvez seja a de escala e precisão das análises. Atividades cotidianas ganham uma dimensão nunca antes observada, e as tecnologias permitem examinar a dinâmica do comportamento humano em sistemas sociais de grande escala.

A análise destas redes sociais de relacionamentos busca entender as semelhanças e diferenças entre redes físicas e online. [LAMPE et. AL 2006]

Os sites de redes sociais de relacionamentos online se diferem entre si em quem pode se unir (estudante, convidado, etc.), quem pode ver o seu perfil, o quanto este perfil é aberto, e o acesso de aplicativos. Alguns sites podem ser acessados por telefone.

Os sites também se diferem no tamanho, com o Facebook apresentando 132 milhões de acessos únicos somente em Junho de 2008. Outra diferença é o público-alvo, como o Orkut, que começou como uma rede social nos Estados Unidos, e hoje 80\% de seus usuários se encontram no Brasil e na Índia. [JOINSON 2008].

Existem várias propostas de estudos de redes sociais online, que entendem a natureza destas redes, segundo Thacker (2004) pela:

- Conectividade: tudo é conectado, nada acontece isoladamente.

Ubiqüidade: conexões ocorrem em todos os lugares, sendo uma propriedade geral do mundo.

- Universalidade: as redes são universais, e suas propriedades gerais abstratas podem descrever, explicar e analisar uma série de fenômenos.

A análise de redes sociais é anterior à análise de redes online. Um trabalho seminal é o do sociólogo Georg Simmel (1950) que diferencia grupos sociais (grupo com foco específico, como a família, a vizinhança, etc.) de redes sociais (uma coleção maior e menos focada de pessoas e grupos com conexões entre grupos).

Em seguida, a hierarquia de necessidades de Maslow (1954) foi 
usada (necessidades fisiológicas, como a troca de mensagens entre segurança, pertencimento, estima, funcionários de uma mesma auto-realização).

O trabalho de Stanley Milgram (1967) do mundo pequeno (ou seis graus de separação) mostrou algumas características de redes sociais, como o fato de que a maioria dos pares de uma rede passa por 6 nós para atingir um indivíduo. Lescovec e Horvitz (2008) obtiveram um índice de 6.6 por um método diferente: os autores construíram uma rede social a partir de 250 bilhões de contas de mensagens instantâneas do MSN Messenger conectando dois indivíduos se eles mantiveram uma conversação no período observado de um mês.

Estes caminhos curtos existentes ainda estão por ser totalmente entendidos e explicados. Watts e Strogatz (1999) observaram que o mundo é altamente agregado, consistindo de ligações que são geograficamente e socialmente similares entre si. A adição de novas conexões causa o surgimento de novos caminhos curtos entre os nós. Um aspecto de sistema de informação surge destes experimentos: além dos caminhos existirem, as pessoas são capazes de encontrá-los.

Este é um comportamento algorítmico, semelhante ao de sistemas postais, por exemplo, sem, contudo, ser implementado especificamente para isto. As amizades dependem da distância [KLEINBERG 2000].

Adamic \& Adar (2005) consideraram como a amizade e a comunicação dependem de noções não-geográficas de "distância", mas sim como a probabilidade de você conhecer alguém ser afetada pelo fato de vocês terem profissões, culturas, cargos similares, etc. Eles estudaram organização quando olharam para pessoas distanciadas na hierarquia.

Os estudos do mundo pequeno focam uma mensagem direcionada. Contudo, na rede social, a maioria das mensagens são irradiadas ("broadcast"), de pessoa a pessoa, "contagiando" e influenciando na formação de opinião, crenças sociais, adoção de novas tecnologias, etc.

Por exemplo, Hill et al (2006) analisam com a adoção de um plano de serviço de telecomunicação por um consumidor depende da conexão deste consumidor com outros que tenham adotado o serviço anteriormente. Este contágio pode ser usado como um princípio de design de sistemas de informação, tais como sistemas de recomendação em comércio eletrônico [LESKOVEC, ADAMIC \& HUBERMAN 2007].

Barabási (2005) mostrou que redes têm lei de potência, são livres de escala, e exibem adesão preferencial. Esta adesão preferencial aplicada às redes online significa que ganhos futuros geralmente são maiores para nós com maior número de conexões.

Em outras palavras, uma onda levanta todos os barcos, um artigo citado torna-se mais citado, e um novato em uma comunidade online se conecta mais geralmente a um membro bem conhecido. Robin Dunbar (1999) mostrou que uma pessoa pode manter, confortavelmente, $\quad 150$ relacionamentos sociais (aproximadamente o tamanho de vilas, unidades táticas, uma legião Romana).

Redes sociais online, com milhões de usuários, também 
trabalham para manter esta escala humana em mente.

Lampe et. al (2006) distinguem "busca social": o uso para achar informações sobre contatos offline; e "pesquisa social": o uso do site para criar novos relacionamentos, algumas vezes com o objetivo de interação offline. Segundo os autores, o uso principal foi o de "manter contato com velhos amigos", sugerindo uma função de capital social para o Facebook.

Os autores também indicam que estes sites servem uma função de observação, permitindo aos usuários "acompanhar as ações, crenças e interesses dos grandes grupos aos quais ele pertence". Alguns sites usam estas características para aumentar o número de usuários, permitindo, por exemplo, associações por escolas, cidades, esportes, etc. encorajando o desenvolvimento de laços baseados em experiências comuns.

No entanto, podemos concluir, ao contrário do que a maioria das pessoas esperavam, que o Orkut, assim como o Facebook, são mais freqüentemente usados para manter contato com as pessoas com as quais não se possui mais contato direto (Offline), saber notícias, ver fotos e etc. É usado também para reencontrar com pessoas que a muito tempo não se via. Com o resultado dessa pesquisa podemos abstrair também que poucas são as pessoas que utilizam esse tipo de site para conhecer novas pessoas através de amigos de amigos.

Golder et. al (2007) reportam que as mensagens são mandadas tanto para amigos (90\%) quanto para pessoas fora da rede local, o que sugere 0 uso de mensagens para manter e construir laços sociais à distância. Os autores argumentam que a manutenção destes laços requer pouco esforço ou investimento, e que a troca de mensagens com amigos distantes é usado para construir capital social.

O campo adota estes modelos, e têm obtido trabalhos significativos, sem contudo levarem em conta os aspectos mais sociais dos fenômenos, como a sua dinamicidade, o capital social, entre outros, por exemplo.

Primo (2003) divide a interação online em duas formas: mútua e reativa. A mútua se caracteriza por relações independentes e processos de negociação; a reativa, por sua vez é limitada por relações determinísticas de estímulo e resposta. Recuero (2005) por sua vez, argumenta que

"É fundamental, portanto, para a análise da organização de uma rede social, a compreensão da interação mediada pelo computador em todos os seus aspectos. É preciso pois, investigar as interações de um grupo social no âmbito do espaço do seu virtual settlement, para que se perceba que essas interações levarão a constituição da estrutura da rede social observada, bem como sua ruptura ou transformação. Elas proporcionam, portanto, também os processos

dinâmicos[...]"

\section{Laço Social e Capital Social}

Uma rede social é composta por um conjunto de dois elementos: atores e suas conexões. No Orkut, os atores podem ser compreendidos por seus usuários, enquanto as conexões podem ser compreendidas pelas relações sociais estabelecidas no site. O seu estudo é focado na estrutura e nas relações, que podem estar em laços sociais .

Segundo Putnam (2000), os laços sociais emergem de um ciclo 
virtuoso de confiança, em associações com objetivos comuns. $\mathrm{O}$ autor argumenta que eles podem ser relacionais, de ligação (de interação) ou associativos, de conexão (de pertencimento). Estes laços estão presentes em sites sociais de relacionamentos, como o Orkut [RECUERO 2005].

Ellison, Steinfield \& Lampe (2007) acrescentam os laços de manutenção de capital, que vem a ser "a habilidade de manter contato com uma rede social após fisicamente se desligar dela."

Os laços podem ainda se sobrepor à classificação de Granovetter (1973), para quem eles podem ser fortes (intimidade, proximidade e intenção de manter relacionamento, com maior troca social, que demandam mais tempo para se estabelecerem. Estes laços se encontram mais freqüentemente em grupos que se valem de mais sistemas para interagir, como o Orkut e outros) ou fracos (relações esparsas, com trocas sociais mais difusas).

Bourdieu (1983) define Capital Social como

"o conjunto dos recursos concretos ou potenciais que estão ligados à posse de uma rede durável de relações mais ou menos institucionalizadas de amizade e reconhecimento mútuo."

Segundo o autor, este conjunto de recursos de um grupo é obtido através do compartilhamento dos recursos individuais, usufruídos por todos, e baseado na reciprocidade.

O capital social está embutido nas relações sociais e é determinado pelo seu conteúdo, cujos recursos são percebidos e apropriados pelos usuários, transformados em outras formas de capital.

Ou seja, o capital social de uma comunidade, seja física ou online, se baseia nos relacionamentos, nos atributos do indivíduo e nos recursos sociais disponíveis, e não é possuído por nenhum indivíduo, mas reside nos relacionamentos entre indivíduos.

O capital social tem sido usado para explicar como alguns indivíduos obtêm mais sucesso usando suas conexões, ganham mais [BELLIVEAU et al 1996], e conseguem empregos, em que "boas conexões ajudam as pessoas a obterem bons empregos" [ERICKSON 2004].

Bertolini e Bravo (2004) categorizam o capital social em: - relacional (relações, laços e trocas que conectam à rede. Podem ser exemplificados com os valores repassados entre amigos e familiares); - normativo (regras de comportamento, como cores, fontes, etc. representando intenção: letras maiúsculas para chamar a atenção, por exemplo);

- cognitivo (conhecimentos comuns, como aqueles que são divulgados para todos, como um convite para uma festa);

- confiança.

- institucional (formais e informais que estruturam o grupo, como as definidas pelo Orkut). Para os autores, estas categorias seriam de primeiro nível (individual, envolvendo as relações, as normas e o conhecimento) e de segundo nível (coletivo, envolvendo confiança e presença de instituições).

\section{Usos e Gratificações}

Usos e Gratificações se referem ao "como e porquê" do uso de uma determinada mídia: as motivações e satisfações que o usuário ganha deste uso. As satisfações podem ser 
baseadas em conteúdo (relacionados com o uso repetido) ou experiência [STAFFORD et al 2004]. Os autores também sugerem que a Internet provê, adicionalmente, um ambiente social, ao oferecer comunicação e interação.

Recuero (2008) discute alguns valores de ganho de capital social percebidos por usuários de blogs: visibilidade; interação; apoio social; reputação; popularidade e autoridade. Por exemplo, a autora encontrou que uma pessoa responsável por um blog tende a replicar informação baseada no ganho de capital social: observouse que comentários e links eram considerados formas importantes de status social, e, portanto, os responsáveis pelos blogs publicavam informações que eles achavam que pudessem trazer tais ganhos.

Joinson (2008) realizou um estudo de usos e gratificações com 137 usuários do site de Relacionamentos Facebook nos Estados Unidos. O estudo levantou dados demográficos básicos (como idade, sexo, etc.), medidas de usos do site (como quantidade de amigos, etc.) e perguntas sobre o que mais dá prazer, qual o uso do site e quais são os usos mais importantes.

Como resultado, Joinson (2008) foi capaz de agrupar as respostas em 7 fatores:

- Fator 1 - Conexão Social Manter contato; reconectar com contatos perdidos, etc.

- Fator $2-$ Identidades
Compartilhadas
interesse; eventos, etc.

- Fator 3 - Fotografias Compartilhamento; visualização. Fator 4 - Conteúdo - Aplicações, etc.

- Fator 5 - Investigação Social - Procura; conhecimento, etc.
- Fator 6 - Navegação Social

na Rede - Ver a rede de "amigos" de outros.

- Fator 7 - Atualizações Novidades; atualizações, etc.

O autor recomenda estes fatores para análises futuras, sob a premissa de que eles são interpretáveis.

\section{Pesquisa}

Este estudo se vale das ciências da rede, de conceitos de capital social e dos fatores achados por Joinson (2008), para verificar como estes fatores se replicariam entre os usuários do Orkut no Brasil. Criado por Orkut Buyukkokten e lançado no Google em 2004, o Orkut é um site de redes de relacionamentos, que cresce exponencialmente, com milhões de usuários entre os jovens do Brasil e da Índia [JOINSON 2008].

A coleta de dados se processou de forma orgânica: o questionário, contendo as perguntas que caracterizariam cada um dos fatores de Joinson (2008), foi colocado online, temporariamente, em uma pagina cedida para a pesquisa. Por ser considerada uma forma mais confiável, foram enviados depoimentos, contendo o link, a todos os contatos. Aos pesquisados foi pedido que respondessem sobre dados demográficos; e, para cada fator, dividido em seus componentes, foi pedido a opinião, a ser expressa em notas de uma escala Likert de 7 valores: 1-Extremamente desimportante; 2 - Muito desimportante. 3 - Um pouco desimportante. 4 - Importante. 5 - Um pouco importante. 6 - Muito importante. 7 - Extremamente importante. 
De forma relacional ou cognitiva [BERTOLINI \& BRAVO 2004], os usuários participaram voluntariamente, respondendo a este questionário entre os dias 10 e 17/11/2008. Embora este período seja bastante curto, notamos a virulência da rede [LESCOVEC ADAMIC \& HUBERMAN 2007], uma vez que, sem divulgação,obtivemos 115 respostas.

A natureza da coleta, combinada com a forma voluntária com que os pesquisados participaram podem ter influenciado os resultados, uma vez que seria razoável supor que os respondentes sejam usuários mais ativos na rede. Um estudo posterior, com uma amostra mais significativa estatisticamente, ou que compare padrões de quem respondeu com quem não respondeu ao questionário, pode ser feito para validar os achados aqui apresentados.

\section{Resultados e Análises}

Apresentamos, a seguir, os fatores e seus componentes, com as notas médias, o desvio padrão e o entendimento dos usos, gratificações e capital social de cada componente.

Observamos que os valores encontrados (média e desvio padrão) são totalmente coincidentes com os valores encontrados por Joinson (2008), o que mostra um padrão de uso semelhante através das culturas americana e brasileira e dos sites Facebook e Orkut.

Os respondentes foram 72 do sexo masculino e 43 do sexo feminino. 22 respondentes têm idade entre $15 \mathrm{e}$ 20 anos; 72 entre 20 e 25 anos e 16 respondentes têm acima de 25 anos.

66 pessoas relataram que acessam o Orkut mais de 5 vezes por semana. 18 ficam menos de meia hora, 35 ficam até uma hora, 20 até duas horas, 15 até duas horas e meia e 26 ficam no Orkut por mais de 3 horas por acesso. 57 possuem mais de 400 amigos, e os demais possuem entre 50 e 400.

\begin{tabular}{|c|c|c|c|}
\hline $\begin{array}{c}\text { Fator } 1 \text { - } \\
\text { Conexão } \\
\text { Social }\end{array}$ & Média & $\begin{array}{l}\text { Desvio } \\
\text { Padrão }\end{array}$ & $\begin{array}{l}\text { Usos Gratifi- } \\
\text { cações }\end{array}$ \\
\hline $\begin{array}{l}\text { Descobrir o que } \\
\text { os velhos } \\
\text { amigos estão } \\
\text { fazendo agora. }\end{array}$ & 4.4649 & 1.6115 & $\begin{array}{l}\text { Relacional; } \\
\text { Institucional; } \\
\text { Interação; } \\
\text { Laços fortes. }\end{array}$ \\
\hline $\begin{array}{l}\text { Reconectar com } \\
\text { pessoas com } \\
\text { quem você } \\
\text { perdeu contato. }\end{array}$ & 5.6522 & 1.3959 & $\begin{array}{l}\text { Relacional; } \\
\text { Institucio-nal; } \\
\text { Interação; } \\
\text { Laços fracos. }\end{array}$ \\
\hline $\begin{array}{l}\text { Conectar-se } \\
\text { com pessoas } \\
\text { que, caso não } \\
\text { houvesse o } \\
\text { Orkut, você } \\
\text { teria perdido } \\
\text { contato. }\end{array}$ & 5.6870 & 1.3854 & $\begin{array}{l}\text { Relacional; } \\
\text { Institucio-nal; } \\
\text { Interação; } \\
\text { Laços fracos. }\end{array}$ \\
\hline $\begin{array}{l}\text { Receber convite } \\
\text { de amigos. }\end{array}$ & 4.2174 & 1.6774 & $\begin{array}{l}\text { Relacional; } \\
\text { Interação; } \\
\text { Populari- } \\
\text { dade; Laços } \\
\text { fracos. }\end{array}$ \\
\hline $\begin{array}{l}\text { Encontrar } \\
\text { pessoas que } \\
\text { você não vê ha } \\
\text { algum tempo. }\end{array}$ & 5.4870 & 1.3854 & $\begin{array}{l}\text { Relacional; } \\
\text { Interação; } \\
\text { Laços } \\
\text { fortes. }\end{array}$ \\
\hline $\begin{array}{l}\text { Manter relação } \\
\text { com pessoas } \\
\text { que você não } \\
\text { vê freqüente/e. }\end{array}$ & 5.3826 & 1.4954 & $\begin{array}{l}\text { Relacional; } \\
\text { Institucio-nal; } \\
\text { Interação; } \\
\text { Laços fracos. }\end{array}$ \\
\hline $\begin{array}{l}\text { Entrar em } \\
\text { contato com } \\
\text { amigos que } \\
\text { estão longe de } \\
\text { casa. }\end{array}$ & 5.6000 & 1.5593 & $\begin{array}{l}\text { Relacional; } \\
\text { Interação; } \\
\text { Laços } \\
\text { fortes. }\end{array}$ \\
\hline
\end{tabular}

Tabela 1. Fator de Conexão Social.

A tabela 1 apresenta itens ligados à manutenção do contato com amigos atuais e com a re-conexão com contatos perdidos. Dependendo da distância (tempo/espaço), os laços podem ser fortes ou fracos. Os capitais sociais relacional, institucional e de interação estão presentes em todos os itens. 


\begin{tabular}{|c|c|c|c|}
\hline $\begin{array}{c}\text { Fator 2 - } \\
\text { Identidades } \\
\text { Compartilhadas }\end{array}$ & Média & $\begin{array}{l}\text { Desvio } \\
\text { Padrão }\end{array}$ & $\begin{array}{l}\text { Usos, } \\
\text { Gratifi- } \\
\text { cações }\end{array}$ \\
\hline $\begin{array}{l}\text { Entrar em grupos } \\
\text { (comunidades) } \\
\text { Comunicar com } \\
\text { pessoas que } \\
\text { pensam da } \\
\text { mesma maneira. }\end{array}$ & 3.6522 & 1.5520 & $\begin{array}{l}\text { Relacional; } \\
\text { Cognitivo; } \\
\text { Institucional; } \\
\text { Interação; } \\
\text { Popularidade; } \\
\text { Laços fracos. } \\
\text { Relacional; } \\
\text { Cognitivo; } \\
\text { Institucional; } \\
\text { Interação; } \\
\text { Popularidade; } \\
\text { Laços fracos. } \\
\text { Relacional; } \\
\text { Cognitivo; } \\
\text { Institucional; } \\
\text { Interação; } \\
\text { Popularidade; } \\
\text { Laços fracos. }\end{array}$ \\
\hline
\end{tabular}

Tabela 2. Identidades Compartilhadas.

A tabela 2 é composta por itens associados aos laços de conexão ("Social browsing") de Lampe et al. (2007), embora não tenhamos dados para concluir se existe ou não o interesse de encontro offline. O site de relacionamento online viabiliza estes comportamentos, em laços fracos, ajudando o usuário a ganhar popularidade.

\begin{tabular}{|c|c|c|c|}
\hline $\begin{array}{c}\text { Fator } 3 \text { - } \\
\text { Fotografias }\end{array}$ & Média & $\begin{array}{l}\text { Desvio } \\
\text { Padrão }\end{array}$ & $\begin{array}{c}\text { Usos e } \\
\text { Gratificações }\end{array}$ \\
\hline $\begin{array}{l}\text { Ver } \\
\text { fotografias }\end{array}$ & 4.1043 & 1.7314 & $\begin{array}{l}\text { Visibilidade; } \\
\text { Interação; } \\
\text { Popularidade; } \\
\text { Laços fortes. }\end{array}$ \\
\hline $\begin{array}{l}\text { Ser marcado } \\
\text { em fotos } \\
\text { (seus } \\
\text { amigos } \\
\text { marcarem } \\
\text { você em } \\
\text { fotos) }\end{array}$ & 2.8783 & 1.7651 & $\begin{array}{l}\text { Visibilidade; } \\
\text { Interação; } \\
\text { Popularidade; } \\
\text { Laços fortes. }\end{array}$ \\
\hline $\begin{array}{l}\text { Marcar fotos } \\
\text { (marcar seus } \\
\text { amigos em } \\
\text { fotos) }\end{array}$ & 2.7652 & 1.7161 & $\begin{array}{l}\text { Visibilidade; } \\
\text { Interação; } \\
\text { Popularidade; } \\
\text { Laços fortes. }\end{array}$ \\
\hline $\begin{array}{l}\text { Compartilha } \\
\text { ndo/postand } \\
\text { o fotos } \\
\text { (colocar } \\
\text { fotos no } \\
\text { álbum) }\end{array}$ & 3.3913 & 1.6508 & $\begin{array}{l}\text { Visibilidade; } \\
\text { Interação; } \\
\text { Popularidade; } \\
\text { Laços fortes. }\end{array}$ \\
\hline
\end{tabular}

A tabela 3 refere-se ao uso de fotografias. Estes usos derivam grandes ganhos de motivação e gratificação, com ganhos de capital social de visibilidade, interação e popularidade.As pessoas gostam de mostrar aos contatos que ela é popular, possui muitos amigos, participa dos eventos atuais. Seria uma boa sugestão a desenvolvedores de sites de relacionamento, que adicionasse uma galeria de eventos que vão acontecer, e dos que já aconteceram, colocando fotos, e promovendo parcerias com os organizadores do evento.

\begin{tabular}{|c|c|c|c|}
\hline $\begin{array}{c}\text { Fator 4- } \\
\text { Conteúdo } \\
\text { (conteúdo } \\
\text { dentro do } \\
\text { Orkut) }\end{array}$ & Média & $\begin{array}{l}\text { Desvio } \\
\text { Padrão }\end{array}$ & $\begin{array}{c}\text { Usos e } \\
\text { Gratificações }\end{array}$ \\
\hline $\begin{array}{l}\text { Aplicações } \\
\text { dentro do } \\
\text { Orkut } \\
\text { (vídeos, } \\
\text { jogos...) }\end{array}$ & 3.1913 & 1.6092 & $\begin{array}{l}\text { Relacional; } \\
\text { Laços fortes. }\end{array}$ \\
\hline Jogar jogos & 1.9739 & 1.4947 & Relacional. \\
\hline $\begin{array}{l}\text { Descobrir } \\
\text { aplicações } \\
\text { porque } \\
\text { algum } \\
\text { amigo seu } \\
\text { adicionou. }\end{array}$ & 2.5739 & 1.5663 & $\begin{array}{l}\text { Laços de } \\
\text { ligação. }\end{array}$ \\
\hline $\begin{array}{l}\text { Enquetes } \\
\text { (pesquisas) }\end{array}$ & 2.7391 & 1.6686 & $\begin{array}{l}\text { Relacional; } \\
\text { Cognitivo; } \\
\text { Interação; } \\
\text { Laços de } \\
\text { ligação. }\end{array}$ \\
\hline
\end{tabular}

Tabela 4. Conteúdos.

A tabela 4 se relaciona com a gratificação de conteúdos. Observa-se que as notas médias são baixas, o que indica que talvez este não seja um item tão importante nos sites de relacionamento online. Os conteúdos não parecem se relacionar com a formação de novos laços, e sim com em fortalecer laços existentes. Os desenvolvedores destes sites devem, portanto, se preocupar com outros

Tabela 3. Fotografias. 
itens de requisitos, que proporcionem mais ganhos de capital social.

\begin{tabular}{|c|c|c|c|}
\hline $\begin{array}{c}\text { Fator } 5 \text { - } \\
\text { Investigação } \\
\text { social }\end{array}$ & Média & $\begin{array}{l}\text { Desvio } \\
\text { Padrão }\end{array}$ & $\begin{array}{l}\text { Usos e } \\
\text { Gratifi- } \\
\text { cações }\end{array}$ \\
\hline $\begin{array}{l}\text { Observar } \\
\text { pessoas } \\
\text { virtualmente. } \\
\text { (olhar o perfil } \\
\text { dos amigos) }\end{array}$ & 2.9391 & 1.8048 & $\begin{array}{l}\text { Normativo; } \\
\text { Laços } \\
\text { fracos de } \\
\text { conexão. }\end{array}$ \\
\hline $\begin{array}{l}\text { Usar a pesquisa } \\
\text { avançada para } \\
\text { buscar tipos } \\
\text { específicos de } \\
\text { pessoas. }\end{array}$ & 3.1304 & 1.9089 & $\begin{array}{l}\text { Normativo; } \\
\text { Laços } \\
\text { fracos de } \\
\text { conexão. }\end{array}$ \\
\hline $\begin{array}{l}\text { Conhecer novas } \\
\text { pessoas. }\end{array}$ & 3.3913 & 1.7480 & $\begin{array}{l}\text { Relacio-nal; } \\
\text { Normativo; } \\
\text { Interação; } \\
\text { Laços fracos } \\
\text { de } \\
\text { conexão. }\end{array}$ \\
\hline $\begin{array}{l}\text { Perseguindo } \\
\text { outras pessoas } \\
\text { (sempre } \\
\text { invadir/monitorar } \\
\text { o Orkut de } \\
\text { alguns amigos). }\end{array}$ & 1.9826 & 1.5879 & $\begin{array}{l}\text { Institucio-nal; } \\
\text { Laços } \\
\text { fracos. }\end{array}$ \\
\hline
\end{tabular}

Tabela 5. Investigação Social.

A tabela 5 apresenta tanto busca "social searching" quanto pesquisa "social browsing" [LAMPE et al 2007]. Usa-se o Orkut tanto para encontrar quanto para ver novas pessoas, bem como para descobrir mais sobre pessoas que se conhece offline.

\begin{tabular}{|c|c|c|c|}
\hline $\begin{array}{c}\text { Fator } 6 \text { - } \\
\text { Navegand } \\
\text { o na rede } \\
\text { social }\end{array}$ & Média & $\begin{array}{l}\text { Desvio } \\
\text { Padrão }\end{array}$ & $\begin{array}{l}\text { Usos e } \\
\text { Gratifi- } \\
\text { cações }\end{array}$ \\
\hline $\begin{array}{l}\text { Olhar os } \\
\text { perfis das } \\
\text { pessoas } \\
\text { que você } \\
\text { não } \\
\text { conhece. }\end{array}$ & 3.0174 & 1.7936 & $\begin{array}{l}\text { Relacional; } \\
\text { Normativo; } \\
\text { Confiança; } \\
\text { Instituciona } \\
\text { I. }\end{array}$ \\
\hline $\begin{array}{l}\text { Ver os } \\
\text { amigos de } \\
\text { outros } \\
\text { amigos }\end{array}$ & 3.3478 & 1.6891 & $\begin{array}{l}\text { Relacional; } \\
\text { Normativo; } \\
\text { Confiança; } \\
\text { Institucio- } \\
\text { nal; } \\
\text { Popularida- } \\
\text { de. }\end{array}$ \\
\hline
\end{tabular}

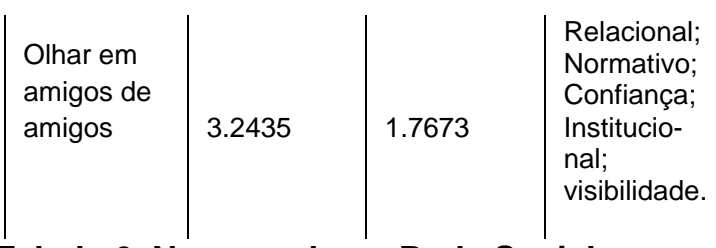

Tabela 6. Navegando na Rede Social.

A tabela 6 se refere-se a uma característica única de sites de relacionamentos online, que é a de permitir conhecer as redes e amigos de outras pessoas, descobrir mais a respeito da pessoa através da rede social de relacionamentos desta pessoa, e pode servir para aumentar a sua própria rede, adicionando amigos de amigos. A gratificação de processo neste caso é bastante forte. Os desenvolvedores de sites de relacionamentos online podem usar este achado para permitir, por exemplo, que esta navegação ocorra entre redes distintas (do Orkut poder ver a rede do Facebook).

\begin{tabular}{|c|c|c|c|}
\hline $\begin{array}{l}\text { Fator } 7 \text { - } \\
\text { Atualizações } \\
\text { do status }\end{array}$ & Média & $\begin{array}{l}\text { Desvio } \\
\text { Padrão }\end{array}$ & $\begin{array}{l}\text { Usos e } \\
\text { Gratifi- } \\
\text { cações }\end{array}$ \\
\hline $\begin{array}{l}\text { Atualizar seu } \\
\text { próprio status. }\end{array}$ & 3.6348 & 1.8431 & $\begin{array}{l}\text { Relacional; } \\
\text { Normativo; } \\
\text { Institucional; } \\
\text { visibilidade; } \\
\text { Aprovação } \\
\text { social; } \\
\text { popularida- } \\
\text { de. }\end{array}$ \\
\hline $\begin{array}{l}\text { Receber } \\
\text { notícias. (de } \\
\text { atualização de } \\
\text { status, perfil, } \\
\text { fotos, } \\
\text { relacionamen- } \\
\text { to...) }\end{array}$ & 3.7217 & 1.7818 & $\begin{array}{l}\text { Relacional; } \\
\text { Normativo; } \\
\text { Institucional; } \\
\text { Interação. }\end{array}$ \\
\hline $\begin{array}{l}\text { Ver o que as } \\
\text { pessoas } \\
\text { colocam como } \\
\text { seu próprio } \\
\text { status. (status } \\
\text { delas) }\end{array}$ & 3.5043 & 1.8291 & $\begin{array}{l}\text { Relacional; } \\
\text { Normativo; } \\
\text { Institucional. }\end{array}$ \\
\hline \multicolumn{4}{|c|}{ Tabela 7. Atualização de Status. } \\
\hline \multicolumn{4}{|c|}{$\begin{array}{l}\text { A tabela } 7 \text { se refere a itens que } \\
\text { m o usuário informado sobre as }\end{array}$} \\
\hline
\end{tabular}


atualizações da rede, como atividades recentes, novas amizades, etc.

Os sites de relacionamento online são um campo vasto e aberto de pesquisas em diversas áreas. Tais pesquisas são úteis para o uso da informação e embasamento de cidadania. Os resultados de usos e gratificações de brasileiros no Orkut, comparáveis com os resultados obtidos por Joinson (2008) para os americanos no Facebook, são apenas uma visão momentânea de uma rede super dinâmica. No entanto, corroboram estudos anteriores de manutenção, re-conexão de amizades, busca por novos relacionamentos.

Um trabalho futuro seria o de acompanhar a evolução destas redes. Por exemplo, pode-se verificar se o hábito de uso vai ampliar os usos, gratificações e capital social; ou se a rede está em processo de estagnação. Algumas das aplicações presentes são de cunho social (ver pessoas da mesma escola, por exemplo), e geralmente são diferentes dos padrões de privacidade. Neste caso, a usabilidade também pode estudar como manter a privacidade e ao mesmo tempo atender a vontade de conhecer e ser conhecido.

\section{Outra preocupação para} trabalhos futuros seria um estudo de variáveis mais detalhado, para determinar e prever o uso da rede: por exemplo, Joinson (2008) encontrou que a gratificação de conteúdo está relacionada ao tempo dispendido no site. E que o uso para fotografias, por exemplo, está relacionado com a freqüência de visitas. Estes achados são de importância para os desenvolvedores, pois se visitas repetidas são motivadas por diferentes usos e gratificações, deve-se também enfatizar a construção de conteúdo.
Os desenvolvedores devem levar em conta os usos, gratificações e ganhos de capital social encontrados ao levantarem requisitos para 0 desenvolvimento de sites de relacionamentos online. Por exemplo, observam-se usos específicos de manutenção e reconexão de amizades, seu uso como ferramenta de observação e conteúdos. Outro ponto a ser averiguado são os diferentes usos por idade, sexo, escolaridade, etc.

\section{Conclusão}

As redes sociais de relacionamento online oferecem uma série de usos e gratificações para o usuário, incluindo os ganhos de capital social tradicional, comunicação, etc. Estes diferentes usos apresentam desafios e oportunidades para os desenvolvedores, que podem levá-los em consideração quando forem desenvolver os próprios sites, seus aplicativos, conteúdos etc.

Estas mesmas preocupações devem ter os empreendedores destes sites, que transformam a sociedade, ao oferecerem novas possibilidades. Por exemplo, encontrar um equilíbrio entre as necessidades de privacidade e de querer conhecer novos usuários. De se expor, para conhecer e ser conhecido; e a de não se expor, para manter a privacidade.

Embora as implicações sociais de usos de sites de relacionamentos fujam ao escopo deste trabalho, é importante observar que a exposição e a capacidade de acompanhar "relacionamentos" em uma ordem de grandeza só possível pela atual tecnologia alteram a maneira como nos relacionamos, e até mesmo como nos entendemos. 
Referências

ADAMIC, L., ADAR, E. (2005) "How to search a social network". Social Networks 27,

3. pp. 187-203.

BARABÁSI,

A-L.

(2005)

"The

architecture of complexity: the structure and the

dynamics of networks, from the web to the cell". KDD 2005. Proceedings of the 11th

ACM SIGKDD Int conf on Knowledge Discovery in data mining.

BELLIVEAU, M., O'REILLY, C.I. \& WADE, J. (1996) "Social capital at the top:

effects of social similarity and status on CEO compensation. Academy of Management Journal, 39(6) pp. 15681593.

BERTOLINI, S. E BRAVO, G. (2004) "Social Capital, a multidimensional concept".

Disponível em

http://www.ex.ac.uk/shipss/politics/rese arch/socialcapital/other/bertolini.pdf acessado em 01/12/2008.

BOURDIEU, P. (1998) "The forms of capital" disponível em

http://www.pontomidia.com.br/raquel/r esources/03.html acessado em 01/12/2008.

CASTELLS, M.A. (1999) "The information age: economy, society and culture".

Oxford: Blackwell.

DUNBAR, R. (1999) "Social Perspectives - getting the message". Interactions, v.6, i.6, pp. 20-25.

ELLISON, N.B., STEINFIELD, C. \& LAMPE, C. (2007) "The benefits of Facebook

'friends': Social capital and college students' use of online social network sites."

Journal of Computer-mediated communication 12(4). Disponível em http://jcmc.indiana.edu/vol12/issue4/elli son.html
ERICKSON, B.H. (2004) "Good networks and good jobs: the value of social capital to employers and employees. In N. Lin, K.S. Cook \& R. S. Burt (eds) Social Capital:

Theory and Research, ch 6 pp. 127158. Aldine Transaction

GOLDER, S.A., WILKINSON, D. \& HUBERMAN, B.A. (2007) "Rhythms of Social

Interaction: Messaging within a massive online network. 3rd International

Conference on communities and Technologies.

GRANOVETTER, M. (1973) "The strength of weak ties". In The American Jounal of

Sociology. V. 78, n. 6

HILL, S., PROVOST, F. \& VOLINSKY, C. (2006) "Network-based marketing: Identifying likely adopters via consumer networks." Statistical Science 21, 2. 256-

278.

JOINSON, A.N. (2008) "Looking at', 'Looking up' ou 'Keeping up' with People?

Motives and Uses of Facebook". CHI 2008 Proceedings - Online Social Networks.

Pp.1027-1036.

KLEINBERG, J. (2000) "The small world phenomenom: an algorithmic perspective. In

Proc of th 32nd ACM Symposium on Theory of Computing. 163-170

LAMPE, C., ELLISON, N. \& STEINFIELD, C.A. (2007) "A familiar Face(book):

profile elements as signals in an online social network. In Proceedings of $\mathrm{CHI}$ 2007,

ACM Press, pp. 435-444.

LESCOVEC, J., ADAMIC, L. \& HUBERMAN, B. (2007) "The dynamics of viral

marketing". ACM transactions on the web 1, 1. 
LESKOVEC, J., HORVITZ, E. (2008) Intercom - XXVIII Congresso "Worldwide buzz: planetary scale Brasileiro de Ciências da views on an Comunicação - Uerj

IM network". Proc of the 17th Int WWW RECUERO, R.C. (2008) "Information conference.

MASLOW, A.H.(1954) "Motivation and A Case

Personality". New York, NY, USA: Study in the Brazilian Blogosphere". Harper \&

ACM Hypertext'08, June 19-21

Row Publishers, Inc.

SIMMEL, G. (1950) "The Stranger," in

MILGRAM, S. (1967) "The small world The sociology of Georg Simmel, K. H. problem". Psychology Today 1. Wolff,

PRIMO, A. (2003) "Interação Mediada Ed. Glencoe, III.,: Free Press, 1950, por Computador: a comunicação e a pp. Ixiv, 445.

educação

THACKER, E. (2004) "Networks,

a distância segundo uma perspectiva Swarms and Multitudes". Disponível sistêmico-relacional." Tese de em

Doutorado.

http://www.ctheory.net/text_file.asp?pic

Apresentada ao Programa de Pós- k=422 acessado em 01/12/2008

Graduação em Informática na Educação, WATTS, D.J. , STROGATZ, S.H. UERJ.

PUTNAM, R.D. (2000) "Bowling world"

Alone". New York: Simon \& Schuster. networks. Nature 393. pp. 440-442 RECUERO, R.C. (2005) "Redes

Sociais no Ciberespaço: uma proposta

de estudo" In 